\title{
AuBr3-Catalyzed Thiooxime-to-Carbonyl Conversion: From Chiral Aliphatic Nitro Compounds to Ketones without Racemization
}

DOI:

10.1021/ol9017722

Link to publication record in Manchester Research Explorer

Citation for published version (APA):

Bures, J., Isart, C., \& Vilarrasa, J. (2009). AuBr3-Catalyzed Thiooxime-to-Carbonyl Conversion: From Chiral Aliphatic Nitro Compounds to Ketones without Racemization. Organic Letters, 11, 4414-4417. https://doi.org/10.1021/ol9017722

Published in:

Organic Letters

\section{Citing this paper}

Please note that where the full-text provided on Manchester Research Explorer is the Author Accepted Manuscript or Proof version this may differ from the final Published version. If citing, it is advised that you check and use the publisher's definitive version.

\section{General rights}

Copyright and moral rights for the publications made accessible in the Research Explorer are retained by the authors and/or other copyright owners and it is a condition of accessing publications that users recognise and abide by the legal requirements associated with these rights.

\section{Takedown policy}

If you believe that this document breaches copyright please refer to the University of Manchester's Takedown Procedures [http://man.ac.uk/04Y6Bo] or contact uml.scholarlycommunications@manchester.ac.uk providing relevant details, so we can investigate your claim.

\section{OPEN ACCESS}




\title{
$\mathrm{AuBr}_{3}$-Catalyzed Thiooxime-to-Carbonyl Conversion: From Chiral Aliphatic Nitro Compounds to Ketones without Racemization
}

\author{
Jordi Burés, Carles Isart, and Jaume Vilarrasa* \\ Departament de Química Orgànica, Facultat de Química, Universitat de Barcelona, \\ Diagonal 647, 08028 Barcelona, Catalonia, Spain
}

jvilarrasa@ub.edu

Received July 31, 2009

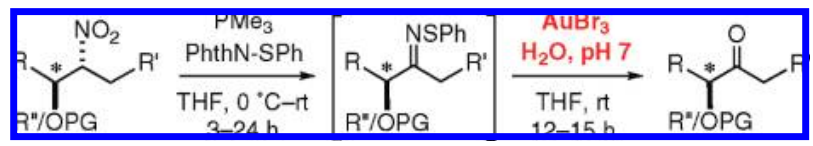

A new variant of the $\mathrm{NO}_{2}$-to-CO transformation (the Nef reaction) that occurs at room temperature under neutral conditions is uncovered. After the conversion of secondary nitroalkanes to phenylsulfenylketimines, these thiooximes are hydrolyzed quantitatively in situ, in $\mathrm{THF}-\mathrm{H}_{2} \mathrm{O}$ at pH 7 , by addition of $\mathrm{AuBr}_{3}$ (but not with other $\mathrm{MX}_{n}$ !). Adducts arising from asymmetric nitro-Michael and nitro-aldol reactions afford 1,4-diketones and $\alpha$-alkoxy ketones, respectively, with full retention of the configuration of the stereocenters $\alpha$ to the $\mathrm{CHNO}_{2} / \mathrm{C}=\mathrm{N}-\mathrm{SPh} / \mathrm{C}=0 \mathrm{groups}$.

Many reactions of gold compounds have been described in the past recent years. ${ }^{1}$ Here we report an unexpected application of $\mathrm{Au}^{3+}$ complexes, which we have incidentally discovered during a screening of inorganic salts in the search for optimum conditions for the hydrolysis of sulfenylketimines to ketones.

(1) Among dozens of reviews on the uses of gold in organic chemistry (the new "gold rush", mainly involving interactions of $\mathrm{Au}(\mathrm{I})$ with multiple $\mathrm{C}-\mathrm{C}$ bonds in the key steps), see the following general summaries: (a) Corma, A.; García, H. Chem. Soc. Rev. 2008, 37, 2096. (b) Hashmi, A. S. K. Rudolph, M. Chem. Soc. Rev. 2008, 37, 1766. (c) Arcadi, A. Chem. Rev. 2008, 108, 3266. (d) Li, Z.; Brouwer, C.; He, C. Chem. Rev. 2008, 108 , 3239. For a mechanistic overview, see: (e) Soriano, E.; Marco-Contelles, J. Acc. Chem. Res. 2009, 42, 1026.

(2) For recent reviews of Nef-like reactions, see: (a) Wolfe, J. P. In Name Reactions for Functional Group Transformations; Li, J. J., Corey, E. J., Eds.; Wiley: Hoboken, 2007; p 645. (b) Ballini, R.; Palmieri, A.; Righi, P. Tetrahedron 2007, 63, 12099. (c) Ballini, R.; Petrini, M. Tetrahedron 2004, 60, 1017. Classical review on the use of $\mathrm{TiCl}_{3}$ : (d) $\mathrm{Mc}$ Murry, J. E. Acc. Chem. Res. 1974, 7, 281. Many methods are too harsh for our purposes (to be applied to $\mathrm{NO}_{2}$-containing polyfunctional fragments, in advanced steps of total syntheses). We have sometimes used an oxidative variant $\left(2 \mathrm{KHSO}_{5} \cdot \mathrm{KHSO}_{4} \cdot \mathrm{K}_{2} \mathrm{SO}_{4}\right.$, Oxone): (e) Ceccherelli, P.; Curini, M.; Marcotullio, M. C.; Epifano, F.; Rosati, O. Synth. Commun. 1998, 28, 3057. However, the necessity of having an alkaline aqueous medium to ensure the presence of nitronate ions and to make Oxone partially soluble, as well as the sensitivitity of several characteristic groups to peroxides, prevented us from using it in other cases.
The conversion of secondary nitro alkanes to ketones is a well-known useful reaction, which connects nitrogen and carbonyl chemistry. ${ }^{2}$ Very recently, we developed a smooth protocol that takes place at room temperature (rt) without strong bases or acids; trimethylphosphine and an activator (ArSSAr, PySeSePy, or PhthN-SePh) were the only reagents required (Scheme 1$)^{3}$

In spite of the mild conditions, the procedure has the limitation that during the reduction of enantiopure nitro compounds, substituted at positions $\alpha$ to the $\mathrm{CHNO}_{2}$ groups, racemic ketones were obtained, ${ }^{3 \mathrm{a}}$ as shown in the second equation of Scheme 1. Such a racemization occurs at the ketimine stage, via the enamines. ${ }^{3 \mathrm{a}, 4}$ To solve this handicap, we stopped the reduction cascade of nitro compounds (1) at sulfenylimines 2 , by means of our protocol that uses $\mathrm{PMe}_{3}$ and $N$-(phenylsulfenyl)phthalimide (PhthN-SPh) in THF at rt. $^{5}$ As indicated in Scheme 2, the key point was then to

(3) (a) Burés, J.; Vilarrasa, J. Tetrahedron Lett. 2008, 49, 441. This method was based on (what we call) the BMZ reaction. (b) Barton, D. H. R.; Motherwell, W. B.; Zard, S. Z. Tetrahedron Lett. 1984, 25, 3707.

(4) This would not be the case if the imine/enamine equilibrium would occur preferably via the $\mathrm{CH}_{2} \mathrm{R}^{\prime}$ moiety (e.g., for $\mathrm{R}^{\prime}=\mathrm{Ar}$ or EWG), but speaking in general the handicap was significant and restricted too much the application of our procedure. 
Scheme 1. $\mathrm{PMe}_{3}$-Mediated Conversion of Secondary Nitro Groups to Imines and Ketones

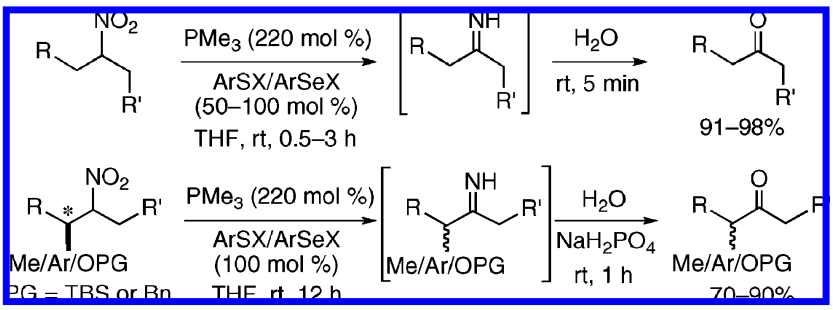

find a way to hydrolyze $\mathbf{2}$ to $\mathbf{3}$ in situ, without first cleaving the $\mathrm{N}-\mathrm{S}$ bond.

Scheme 2. How to Hydrolyze Carefully $N$-(Phenylsulfenyl)ketimines ( $S$-Phenylthiooximes, 2) to Ketones

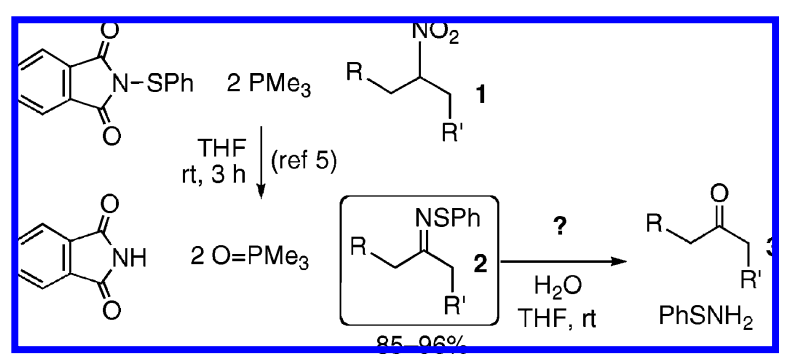

Simple $N$-phenylsulfenylimines such as that of cyclohexanone undergo hydrolysis on moist silica, but those that are sterically crowded require strongly acidic media. ${ }^{6}$ Since esters, acetals, and other protecting groups that could contain polyfunctional nitro derivatives would not survive under these conditions, and since chiral $\alpha$-substituted thiooximes and ketones may racemize at very low and high $\mathrm{pH}$ values, we imposed ourselves the limitation of operating without heating, in the absence of Brönsted acids ${ }^{7}$ and as close as possible to $\mathrm{pH} 7$.

A screening of the potential catalysts (Lewis acids, with thiophilic and relatively nontoxic transition-metal cations, which do not decompose in water) was undertaken with a model compound (2a), ${ }^{5}$ in $\mathrm{THF}-\mathrm{H}_{2} \mathrm{O}$, as shown in Table 1 .

Polymeric salts (MX) and, in general, inorganic compounds that are scarcely soluble in $\mathrm{THF}-\mathrm{H}_{2} \mathrm{O}$ were inactive (as it was $\mathrm{CuO}$, not included in Table 1), whereas $\mathrm{CuBr}_{2}$ (entry 6), $\mathrm{AuCl}_{3}$ (entries 17 and 18), $\mathrm{AuBr}_{3}$ (entries 21-24),

(5) Burés, J. Isart, C. Vilarrasa, J. Org. Lett. 2007, 9, 4635. In Table 1, entry 4 , the oxime should have been depicted as the $Z$ isomer.

(6) (a) Most of our sulfenylimines underwent hydrolysis on warming with $1 \mathrm{M} \mathrm{HCl}$ or with Amberlite IR-120 (pH 2.2), but racemization or epimerization was then produced, as well as the cleavage of various protecting groups. (b) To our knowledge, only the cleavage of tritylsulfenylketimines, by an excess of $\mathrm{AgNO}_{3}$ (and a different mechanism) has been described: Branchaud, B. P. J. Org. Chem. 1983, 48, 3531.

(7) By adding $1 \mathrm{M} \mathrm{HCl}$ or $1 \mathrm{M} \mathrm{HBr}$ to a THF solution of $\mathbf{2 a}$, hydrolysis to ketone 3a was complete after stirring overnight. However, as mentioned, these conditions did not suit us, as we plan to apply the reaction on acidsensitive polyfunctional substrates.
$\mathrm{FeBr}_{3}$ (entries 34 and 35), and $\mathrm{InBr}_{3}$ (entry 43) were the most active. These metallic ions, being harder Lewis acids than their respective $\mathrm{M}^{+}$and/or $\mathrm{M}^{2+}$ ions, lower the $\mathrm{pH}$ of the medium (by partial hydrolysis). Part of their performance may be due to the inherently low $\mathrm{pH}$ of their aqueous solutions, but not exclusively. Moreover, it is remarkable that only $\mathrm{AuBr}_{3}$-derived species did not lose their activity when the reaction medium was partially or fully neutralized $\left(\mathrm{AuBr}_{3}\right.$ was even better than $\mathrm{AuCl}_{3}$ in this regard, compare entry 24 to entry 20). As known, insoluble hydroxides or hydrated oxides of $\mathrm{Cu}(\mathrm{II}), \mathrm{Fe}(\mathrm{III})$, and $\mathrm{In}(\mathrm{III})$ were formed when the solutions of their $\mathrm{MX}_{n}$ salts were neutralized. On the other hand, $\mathrm{AuBr}_{3}$ did not give a precipitate when aqueous $\mathrm{NaOH}$ was added to neutralize the solution. ${ }^{8}$ Thus, we attribute the activity of $\mathrm{Au}(\mathrm{III})$ to the formation of soluble $\left[\operatorname{AuBr}_{x}(\mathrm{OH})_{y}(\mathbf{2 a})\right]^{3-x-y}$ species where 2a replaces one or two ligands of the inner sphere of the central atom. Coordination of $\mathrm{Au}$ (III) with the $\mathrm{S}$ atom and/or $\mathrm{N}-\mathrm{S}$ group of thiooximes is plausible. ${ }^{9}$

At $\mathrm{pH}$ 7, when the amount of $\mathrm{AuBr}_{3}$ was reduced to 0.3 (entries 25-27) and to 0.1 equiv (entry 28) the hydrolysis percentages fell. Given the price of gold and $\mathrm{AuBr}_{3}$ the requirement of 0.5 equiv of catalyst would be a drawback for large-scale applications.

Since the hydrolysis coproduct $\left(\mathrm{PhSNH}_{2}\right)$ is expected to be more basic and nucleophilic than $\mathbf{2 a}$, it may coordinate the central atom of the complex more strongly, "poisoning the catalyst". To eliminate $\mathrm{PhSNH}_{2}$ (and PhSNHSPh and $\left.\mathrm{NH}_{3}\right)^{10}$ we added isopentyl nitrite to the reaction mixture. At $\mathrm{pH} 7$, isopentyl nitrite alone did not react with $\mathbf{2 a}$, but it did react with $\mathrm{ArSNH}_{2}$ (checked independently). ${ }^{11}$ The hydrolysis of 2a was complete at $\mathrm{pH} 7$ with 0.3 equiv of $\mathrm{AuBr}_{3}$ and 0.4 equiv of RONO (overnight at rt). To our delight, with 0.8 equiv of RONO we could reduce the amount of $\mathrm{AuBr}_{3}$ to $10 \mathrm{~mol} \%$. $^{12}$

With optimum protocols for the hydrolysis of $2 \mathbf{a}$ in hand, we subjected another simple nitro compound, racemic $\mathbf{1 b}$, and the stereopure or scalemic nitro derivatives $(\mathbf{1 c}-\mathbf{k})$ shown in Table 2 to the cheapest protocol. Both stepsreduction of $\mathbf{1}$ to $\mathbf{2}$ and hydrolysis of $\mathbf{2}$-were carried out in one pot. The commercially available THF solution of $\mathrm{PMe}_{3}$

(8) (a) Baes, C. F.; Mesmer, R. E. The Hydrolysis of Cations; Wiley: New York, 1976; pp 279-285. (b) Usher, A.; McPhail, D. C.; Brugger, J. Geochim. Cosmochim. Acta 2009, 73, 3359 (a spectrophotometric study of aqueous $\mathrm{Au}(\mathrm{III})$ halide-hydroxide complexes). Also see ref 1a.

(9) On the other hand, oximes $\mathrm{PhC}(=\mathrm{N}-\mathrm{OBn}) \mathrm{Me}$ and $\mathrm{PhC}(=\mathrm{N}-\mathrm{OPh}) \mathrm{Me}$ are not hydrolyzed under the conditions of entry 24 of Table 1 .

(10) Simple sulfenamides $\left(\mathrm{RSNH}_{2}\right)$ may disproportionate to RSNHSR and $\mathrm{NH}_{3}$ : (a) Bao, M.; Shimizu, M.; Shimada, S.; Tanaka, M. Tetrahedron 2003, 59, 303. (b) Davis, F. A.; Friedman, A. J.; Kluger, E. W.; Skibo, E. B.; Fretz, E. R.; Milicia, A. P.; LeMasters, W. C.; Bentley, M. D.; Lacadie, J. A.; Douglass, I. B. J. Org. Chem. 1977, 42, 967. For entries to the chemistry of sulfenamides, see: (c) Koval, I. V. Russ. J. Org. Chem. 2005, 41, 386. (d) Davis, F. A.; Mancinelli, P. A. J. Org. Chem. 1978, 43, 1797. Recent review of $\mathrm{N}-\mathrm{S}$ bond-containing compounds: (e) Davis, F. A. J. Org. Chem. 2006, 71, 8993.

(11) (a) Any alkyl nitrite capable of nitrosating and hence decomposing $\mathrm{ArSNH}_{2}$ and $\mathrm{NH}_{3}$ should work. No PhSH was detected; according to TLC and ${ }^{1} \mathrm{H}$ NMR, PhSSPh was formed predominantly. (b) $\mathrm{C}_{5} \mathrm{H}_{11} \mathrm{ONO}$ alone reacted with 1a at low $\mathrm{pH}$ (1.5 equiv was required to fully decompose 1a, overnight at rt, $\mathrm{pH} 4.2$ ), but not at all at $\mathrm{pH} 7$.

(12) On the other hand, the addition of $\mathrm{NaNO}_{2}(80 \mathrm{~mol} \%)$ instead of $\mathrm{C}_{5} \mathrm{H}_{11} \mathrm{ONO}$ to the mixture of $2 \mathrm{a}$ with $\mathrm{AuBr}_{3}(10 \mathrm{~mol} \%)$ at $\mathrm{pH} 7 \mathrm{did}$ not improve the outcome of entry 28 of Table 1. 
Table 1. Potential Catalysts for the Hydrolysis of $\mathbf{2} \mathbf{a}^{a}$

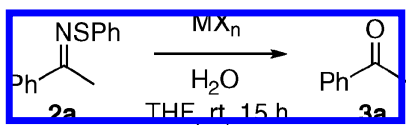

\begin{tabular}{|c|c|c|c|c|}
\hline entry & additive $\left(\mathrm{MX}_{\mathrm{n}}\right)$ & equiv & $\mathrm{pH}$ conditions & $\%$ of $\mathbf{3 a}$ \\
\hline 1 & $\mathrm{Cu}_{2} \mathrm{Cl}_{2}$ & 1.0 & & $0-20^{b}$ \\
\hline 2 & $\mathrm{Cu}_{2} \mathrm{Cl}_{2}$ & 1.0 & buffered at $\mathrm{pH} 4.0$ & $0-20^{b}$ \\
\hline 3 & $\mathrm{CuI}$ & 1.0 & & 0 \\
\hline 4 & $(\mathrm{CuOTf})_{2}{ }^{c}$ & 0.5 & & 11 \\
\hline 5 & $\mathrm{CuCl}_{2} \cdot 2 \mathrm{H}_{2} \mathrm{O}$ & 1.0 & & 43 \\
\hline 6 & $\mathrm{CuBr}_{2}$ & 1.0 & pH measured $=\mathbf{3 . 0}$ & 100 \\
\hline 7 & $\mathrm{CuBr}_{2}$ & 0.5 & $\mathrm{pH}$ measured $=3.5$ & 71 \\
\hline 8 & $\mathrm{CuBr}_{2}$ & 0.1 & & 23 \\
\hline 9 & $\mathrm{CuBr}_{2}$ & 1.0 & buffered at $\mathrm{pH} 7.0$ & 5 \\
\hline 10 & $\mathrm{CuBr}_{2}$ & 1.0 & basified up to $\mathrm{pH} 10.0$ & 0 \\
\hline 11 & $\mathrm{Cu}(\mathrm{OAc})_{2}$ & 1.0 & $\mathrm{pH}$ measured $=5.5$ & 16 \\
\hline 12 & $\mathrm{Cu}(\text { acac })_{2}$ & 1.0 & & 0 \\
\hline 13 & $\mathrm{Cu}(\mathrm{OTf})_{2}$ & 1.0 & & 0 \\
\hline 14 & $\mathrm{AgNO}_{3}$ & 1.0 & & 0 \\
\hline 15 & $\mathrm{AgF}$ & 1.0 & & 0 \\
\hline 16 & $\mathrm{AuCl}^{d}$ & 1.0 & & 0 \\
\hline 17 & $\mathrm{AuCl}_{3}$ & 1.0 & & 100 \\
\hline 18 & $\mathrm{AuCl}_{3}$ & 0.5 & pH measured $=0.9$ & 100 \\
\hline 19 & $\mathrm{AuCl}_{3}$ & 0.5 & adjusted at $\mathrm{pH} 6.0$ & 63 \\
\hline 20 & $\mathrm{AuCl}_{3}$ & 0.5 & adjusted at $\mathrm{pH} 7.0$ & 10 \\
\hline 21 & $\mathrm{AuBr}_{3}$ & 1.0 & pH measured $=1.2$ & 100 \\
\hline 22 & $\mathrm{AuBr}_{3}$ & 0.5 & & 100 \\
\hline 23 & $\mathrm{AuBr}_{3}$ & 0.5 & adjusted at pH 4.0 & 100 \\
\hline 24 & $\mathrm{AuBr}_{3}$ & 0.5 & adjusted at pH 7.0 & $100^{e}$ \\
\hline 25 & $\mathrm{AuBr}_{3}$ & 0.3 & $\mathrm{pH} 4.6$ & 67 \\
\hline 26 & $\mathrm{AuBr}_{3}$ & 0.3 & $\mathrm{pH} 6.7$ & 56 \\
\hline 27 & $\mathrm{AuBr}_{3}$ & 0.3 & $\mathrm{pH} 8.9$ & 6 \\
\hline 28 & $\mathrm{AuBr}_{3}$ & 0.1 & & 26 \\
\hline 29 & $\mathrm{ZnCl}_{2}$ & 1.0 & & 3 \\
\hline 30 & $\mathrm{ZnBr}_{2}$ & 1.0 & & 11 \\
\hline 31 & $\mathrm{FeCl}_{2}$ & 1.0 & & 23 \\
\hline 32 & $\mathrm{CoCl}_{2} \cdot 6 \mathrm{H}_{2} \mathrm{O}$ & 1.0 & & 0 \\
\hline 33 & $\mathrm{NiCl}_{2} \cdot 6 \mathrm{H}_{2} \mathrm{O}$ & 1.0 & & 0 \\
\hline 34 & $\mathrm{FeBr}_{3}$ & 1.0 & pH measured $=0.2$ & 100 \\
\hline 35 & $\mathrm{FeBr}_{3}$ & 0.5 & & 100 \\
\hline 36 & $\mathrm{FeBr}_{3}$ & 0.1 & & 24 \\
\hline 37 & $\mathrm{FeBr}_{3}$ & 1.0 & adjusted at $\mathrm{pH} 4.0$ & 8 \\
\hline 38 & $\mathrm{Sc}(\mathrm{OTf})_{3}$ & 1.0 & & 62 \\
\hline 39 & $\mathrm{LaCl}_{3} \cdot 7 \mathrm{H}_{2} \mathrm{O}$ & 1.0 & & 0 \\
\hline 40 & $\mathrm{CeCl}_{3} \cdot 7 \mathrm{H}_{2} \mathrm{O}$ & 1.0 & adjusted at $\mathrm{pH} 7.0$ & 0 \\
\hline 41 & $\mathrm{CAN}^{f}$ & 1.0 & adjusted at $\mathrm{pH} 7.0$ & 0 \\
\hline 42 & $\mathrm{Yb}(\mathrm{OTf})_{3}$ & 1.0 & & 6 \\
\hline 43 & $\mathrm{InBr}_{3}$ & 1.0 & pH measured $=0.0$ & 100 \\
\hline 44 & $\mathrm{InBr}_{3}$ & 1.0 & adjusted at $\mathrm{pH} 7.0$ & 0 \\
\hline 45 & none & & & 0 \\
\hline 46 & silicagel & & & 0 \\
\hline 47 & dil. $\mathrm{HBr}$ & & $\mathrm{pH} 1.5$ & 0 \\
\hline 48 & dil. $\mathrm{HBr}$ & & $\mathrm{pH} 3.0$ & 0 \\
\hline
\end{tabular}

${ }^{a}$ To $2 \mathrm{a}(0.3 \mathrm{mmol})$ in $1 \mathrm{~mL}$ of THF (unless otherwise indicated) a solution or suspension of the additive (possible catalyst) in $1 \mathrm{~mL}$ of $\mathrm{H}_{2} \mathrm{O}$ ( $\mathrm{pH}$ 6.9-7.0) was added, and the mixture was stirred vigorously overnight; in some cases (indicated) the $\mathrm{pH}$ values were adjusted with $1 \mathrm{M} \mathrm{NaOH}$ (buffering effects were noted) or by addition of standard phosphate buffers. A Crison pHmeter was used. ${ }^{b}$ We later confirmed that only commercial samples contaminated with $\mathrm{CuCl}_{2}$ showed catalytic activity (no hydrolysis occurred with pure $\left.\mathrm{Cu}_{2} \mathrm{Cl}_{2}\right)$. ${ }^{c}$ Commercially available $\mathrm{Cu}_{2}(\mathrm{OTf})_{2}{ }^{\circ} \mathrm{C}_{6} \mathrm{H}_{6}$; identical result with commercial $\mathrm{Cu}_{2}(\mathrm{OTf})_{2} \cdot \mathrm{C}_{7} \mathrm{H}_{8} \cdot{ }^{d} \mathrm{AuCl}$ is insoluble in $\mathrm{H}_{2} \mathrm{O} .{ }^{e}$ Identical result in 9:1 THF- $\mathrm{H}_{2} \mathrm{O}$; the reaction was slower $(85 \%$ of conversion) in 9:1 $\mathrm{CH}_{3} \mathrm{CN}-\mathrm{H}_{2} \mathrm{O} .{ }^{f} \mathrm{Ce}\left(\mathrm{NH}_{4}\right)_{2}\left(\mathrm{NO}_{3}\right)_{6}$.
Table 2. From Chiral Nitro Derivatives to Ketones ${ }^{a}$
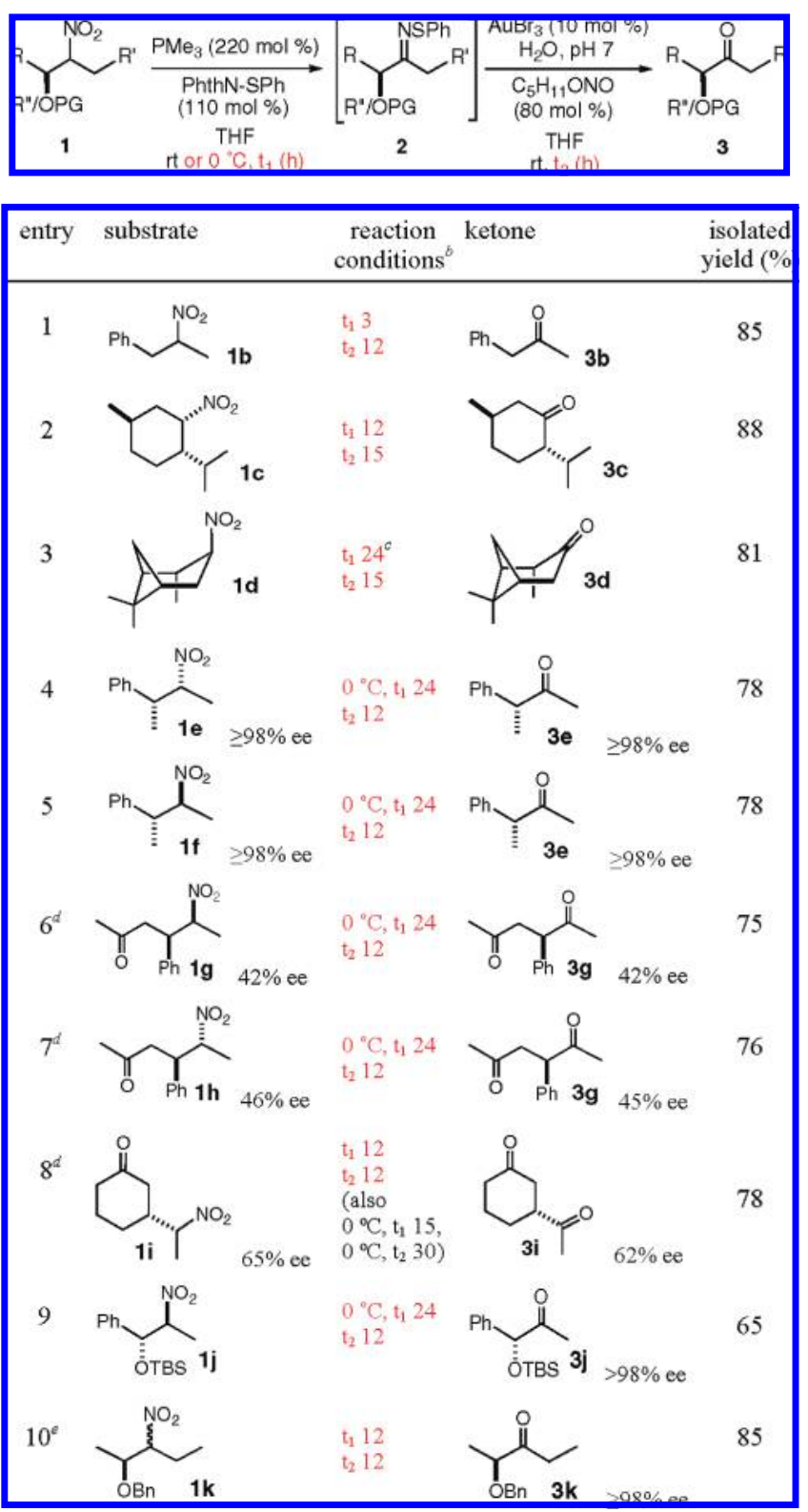

${ }^{a}$ Unless otherwise indicated, both steps were carried out at rt. Workup: after dilution of the final $\mathrm{THF}-\mathrm{H}_{2} \mathrm{O}$ solution with more water and extraction with $\mathrm{CH}_{2} \mathrm{Cl}_{2}$ several times, only $3, \mathrm{PhSSPh}$, and phthalimide derivatives were extracted (as $\mathrm{Me}_{3} \mathrm{PO}$ is very soluble in water and remains in the aqueous layer, together with the brownish gold complexes); $\mathrm{PhSSPh}$ was easily removed by filtration through silica (elution with hexane). Ee values were determined as explained in the Supporting Information. ${ }^{b} t_{1}, t_{2}$, and experiments carried out at $0{ }^{\circ} \mathrm{C}$ (instead of at rt) are indicated. ${ }^{c}$ Six-hundred molar percent of $\mathrm{PMe}_{3}$ and $300 \mathrm{~mol} \%$ of PhthN-SPh were added. ${ }^{d}$ Nitro compounds prepared by organocatalytic addition of nitroethane to the corresponding enones, with trans-2,5-dimethylpiperazine as the base. ${ }^{13 e} \mathbf{1 k}$ as a 1:1 syn/anti mixture.

was used as the medium for the first step. After elimination of the slight excess of $\mathrm{PMe}_{3}$ under vacuum, the aqueous neutral (buffered) solution of $\mathrm{Au}(\mathrm{III})$ and the alkyl nitrite were added and stirring was maintained at rt until the complete disappearance of $\mathbf{2}$.

It is remarkable that the hydrolyses (second step) were always practically quantitative; in fact, only the starting 
materials and expected hydrolysis products were detected by TLC and NMR.

On the other hand, the first step (when sulfenylketimines were formed, isolated, and purified by chromatography) took place in $\mathbf{8 0 - 9 0 \% ~ y i e l d s . ~ A s ~ a n ~ e x c e p t i o n , ~ i n ~ t h e ~} \mathbf{1} \mathbf{j}-\mathbf{2} \mathbf{j}-\mathbf{3 j}$ sequence (entry 9) the yield was moderate, but it was due to the unavoidable formation of Beckmann fragmentation byproducts during the first step. ${ }^{5}$ In fact, these secondary reactions are known to be inherent to all reactions involving oximes, thiooximes, etc., if stable cationic intermediates can be formed.

One advantage of our procedure is that it can be used to prepare chiral 1,4-dicarbonyl compounds from the organocatalytic conjugate addition of nitroalkanes to enones (entries 6-8). In the case of $\mathbf{3 g}$ (entries 6 and 7), 2,5-dimethyl-3phenylpyrrole was not formed at all. ${ }^{14}$ Compounds arising from asymmetric nitro-aldol (Henry) reactions, such as those of entries 9 and 10, are also amenable to our protocol.

As final tests, we reduced the amount of $\mathrm{AuBr}_{3}$ to $5 \mathrm{~mol} \%$ and $2 \mathrm{~mol} \%$. We subjected $\mathbf{2 a}$ to hydrolysis at $\mathrm{pH} 7$ and $\mathrm{rt}$ as in Table 2, with $100 \mathrm{~mol} \%$ of $\mathrm{C}_{5} \mathrm{H}_{11} \mathrm{ONO}$. With $5 \mathrm{~mol} \%$ of $\mathrm{AuBr}_{3}$, stirring for $30 \mathrm{~h}$ was sufficient for the complete disappearance of this sulfenylketimine and its full conversion to ketone 3a. With 2 mol \% of $\mathrm{AuBr}_{3}, 5$ days were required; ${ }^{15}$ the hydrolysis was slower, as expected, but still feasible.

(13) (a) Hanessian, S.; Shao, Z.; Warrier, J. S. Org. Lett. 2006, 8, 4787, and references therein. (b) Mitchell, C. E. T.; Brenner, S. E.; Garcia-Fortanet, J.; Ley, S. V. Org. Biomol. Chem. 2006, 4, 2039. Instead of (S)-proline or a bicyclo[3.1.0]-derivative of Pro and instead of $(S)$-5-(pyrrolidin-2yl)tetrazole, we used Seebach's bicyclic oxazolidinone (the aminal of Pro and ${ }^{t} \mathrm{BuCHO}$ ). See: (c) Isart, C.; Burés, J.; Vilarrasa, J. Tetrahedron Lett. 2008, $49,5414$.

(14) Pyrrole formation is unavoidable in most reductions of $\gamma$-nitro ketones, since the intermediate oximes or imines react in situ with the $\mathrm{CO}$ groups (formation of five-membered rings). Cf. refs $2 \mathrm{~d}$ and $3 \mathrm{~b}$. Zard et al. took advantage of this reaction to prepare various interesting pyrroles: (a) Quiclet-Sire, B.; Thevenot, I.; Zard, S. Z. Tetrahedron Lett. 1995, 36, 9469. (b) Barton, D. H. R.; Motherwell, W. B.; Simon, E. S.; Zard, S. Z. J. Chem. Soc. Perkin Trans. 1 1986, 2243. (c) Barton, D. H. R.; Zard, S. Z. Chem. Commun. 1985, 1098. Under the conditions of Scheme 1, $\gamma$-nitro acyclic ketones give pyrrole derivatives almost quantitatively.

(15) Experiments carried out in parallel, at rt and $\mathrm{pH} 7$ as always, with only $\mathrm{C}_{5} \mathrm{H}_{11} \mathrm{ONO}$ or $\mathrm{NaNO}_{2}$, without $\mathrm{AuBr}_{3}$, did not affect 2a.
Thus, the sulfenylimino groups can be hydrolyzed at neutral buffered $\mathrm{pH}$ and at rt only (to date) with $50 \mathrm{~mol} \%$ of $\mathrm{AuBr}_{3}$ or with $2-10 \mathrm{~mol} \%$ of $\mathrm{AuBr}_{3}$ and stoichiometric or substoichiometric amounts of RONO.

In summary, a very smooth two-step one-pot procedure for the conversion of secondary nitro groups to ketones has been disclosed. As pursued by the senior author for a longtime, it works at $\mathrm{rt}$ (or at $0{ }^{\circ} \mathrm{C}$, if required) and under neutral conditions. The first step, the conversion of secondary nitro groups to sulfenylketimines, ${ }^{3 \mathrm{a}}$ has been applied here successfully, for the first time, to various chiral compounds arising from organocatalytic reactions or stereoselective variants of venerable reactions. The second step-the hydrolysis of these sulfenylimines-involves the use of $\mathrm{AuBr}_{3}$, which among the large number of $\mathrm{MX}_{\mathrm{n}}$ salts examined is the only one that catalyzes such hydrolyses at $\mathrm{pH} 7$. Therefore, for the first time to the best of our knowledge, we have taken advantage of a practical feature of $\mathrm{AuBr}_{3}$ : the solubility and stability of $\left[\mathrm{AuBr}_{x}(\mathrm{OH})_{y}\right]^{3-x-y}$ complexes, which permits thiooximes to coordinate with them and undergo the desired hydrolysis under the mildest possible conditions (compatible with $\alpha$-stereocenters and a plethora of protecting groups). As the first step was originally inspired in the BMZ reaction, ${ }^{3 \mathrm{~b}}$ the overall protocol might be called the Vilarrasa-BMZ Nef-type procedure or something similar.

Acknowledgment. The Spanish Government (MEC, MICINN) is acknowledged for grant CTQ2006-15393 (and earlier grants, during which the objective was conceived) as well as for a studentship to J.B. (Feb 2004-Jan 2008). The Universitat of Barcelona is acknowledged for a studentship to C.I. (since Oct 2006).

Supporting Information Available: Additional experimental details. This material is available free of charge via the Internet at http://pubs.acs.org.

OL9017722 